Original Article

Journal of Epilepsy Research pISSN 2233-6249 / eISSN 2233-6257

Received February 22, 2018

Revised July 25, 2018

Accepted July 27, 2018

Corresponding author:

Lekha Saha, MD, DM

Department of Pharmacology, Postgraduate Institute of Medical Education and Research (PGIMER), Sector 12, Chandigarh 160012 India

Tel. +91-172-2755253, +91-9463503752

Fax. +91-172-2744401

E-mail; lekhasaha@rediffmail.com

\title{
Anti-Oxidant and Anti-Apoptotic Effects of Berberine in Pentylenetetrazole-Induced Kindling Model in Rat
}

\author{
Vaishali Guna, MD¹, Lekha Saha, MD, DM', Alka Bhatia, MD², Dibyajyoti Banerjee, MD²,
} Amitava Chakrabarti, MD, DM ${ }^{1}$

Departments of ${ }^{1}$ Pharmacology, ${ }^{2}$ Experimental Medicine and Biotechnology, Postgraduate Institute of Medical Education and Research (PGIMER), Chandigarh, India

\begin{abstract}
Background and Purpose: Berberine (BBR) is derived from the Berberis species and has demonstrated beneficial effects in various neurodegenerative disorders in animal models. The objective of this study was to evaluate the antiepileptic, antioxidative, and anti-apoptotic effects of BBR in a pentylenetetrazole (PTZ)-induced kindling model of epilepsy in rats.
\end{abstract}

Methods: A total of 30 male Wistar rats were randomly assigned to receive BBR $(100 \mathrm{mg} / \mathrm{kg}$, oral), sodium valproate $(200 \mathrm{mg} / \mathrm{kg}$, i.p.), or saline $(0.9 \% \mathrm{NaCl}$, i.p.) followed by PTZ $(35 \mathrm{mg} / \mathrm{kg}$, i.p.) on alternate days until the animal developed kindling or for 10 weeks. Histopathological examination of the hippocampus; DNA fragmentation study; tests for malondialdehyde, superoxide dismutase, glutathione peroxidase, and reduced glutathione; and gene expression studies (nrf2, bcl-2, bax, and caspase 3) were conducted on whole brain tissue after 10 weeks or kindling.

Results: The percentage of kindled animals, histopathological score, malondialdehyde level, and caspase 3 gene expression were significantly lower in the BBR group than in the PTZ group. Superoxide dismutase levels, reduced glutathione levels, and bcl-2 gene expression were significantly higher in the BBR group than in the PTZ group.

Conclusions: The present study demonstrated the anti-epileptogenic effect of BBR, which may be due to antioxidant and anti-apoptotic properties of the PTZ-induced kindling model of epilepsy. (2018;8:66-73)

Key words: Berberine, Pentylenetetrazol (PTZ) kindling model, Antioxidants, Anti-apoptotic

\section{Introduction}

Epilepsy is among the most widely established chronic neurological disorders and affects more than 50 million people worldwide. ${ }^{1}$ The incidence of epilepsy is $0.5-2 \%$, among which $30 \%$ is drug refractory. Epilepsy is characterized by recurrent unprovoked seizures. The risk factors for epilepsy include central nervous system infections, stroke, brain tumors, genetic epilepsy, prolonged fever and associated seizures, and other occurrences of status epilepticus. ${ }^{2}$ The pathophysiological process of epilepsy begins even before the first seizure occurs and this latent period is known as epileptogenesis. ${ }^{3}$ Some of the underlying mechanisms of the initiation and progression of epilepsy after an initial brain insult include oxidative stress from increased reactive oxygen radicals, apoptosis induction, inflammation, immune modulation, and blood-brain barrier dysfunction. ${ }^{4-6}$ Recent studies have shown that nrf2 is the primary transcription factor activated following oxida- tive stress in epilepsy. ${ }^{7}$ This factor in turn stimulates the expression of antioxidant enzymes, such as hemoxygenase-1, glutathione peroxidase (GPX), and superoxide dismutase (SOD), and reduces malondialdehyde (MDA) levels, which corresponds to lipid peroxidation following oxidative stress. ${ }^{7}$ Repeated seizures may also lead to neuronal cell loss, which further contributes to epileptogenesis. ${ }^{8}$ The activation of the intrinsic apoptotic pathway by the bcl-2 family of apoptotic proteins (bax, bim, bid, bcl-2) is predominantly seen in epilepsy. ${ }^{9}$

Berberine (BBR) is an alkaloid derived from herbs of the Berberis species and has long been used in Chinese medicine. Studies have demonstrated its advantageous role in many neurodegenerative and psychiatric disorders, including Alzheimer's disease, schizophrenia, depression, and anxiety in animal models. ${ }^{10}$ The neuroprotective action of BBR is due to its antioxidant and anti-inflammatory properties. $^{10,11}$ In vitro studies involving neuronal cell lines have shown that BBR stimulates PI3K/AKt/PKB signaling, which induces 
up-regulation of the hemoxygenase-1 and SOD antioxidant enzymes through translocation of nrf2 to the nucleus. ${ }^{11}$ The transcription factor nrf2 may mediate the expression of antioxidant enzymes and proteins that are expressed following stress, thus preventing cellular damage from free radical production. ${ }^{12}$ Because of the increased interest in the clinical uses of BBR, the molecular details of the antioxidant and anti-apoptotic action of BBR merit further investigation. Therefore the present study was conducted on the effects of BBR in a pentylenetetrazole (PTZ)-induced kindling model of epileptogenesis and its mechanism in rats.

\section{Methods}

\section{Chemicals and drugs}

PTZ, sodium valproate (SV), and BBR chloride (Pubchem CID: 12456) of analytical grade were purchased from Sigma Aldrich (Bangalore, India). A real-time polymerase chain reaction (RT-PCR) kit was obtained from Thermo Fisher Scientific (Mumbai, India). Sodium dodecyl sulphate, thiobarbituric acid (TBA), nitroblue tetrazolium, hydroxylamine hydrochloride, reduced glutathione (GSH), and dinitrobenzoic acid reagents were procured from Sisco Research Laboratories (Mumbai, India), and Trizol reagent was procured from Life Technologies (Carlsbad, CA, USA).

\section{Animals}

Young male Wistar rats weighing 200-250 g were used in the present study. The animals were kept in a $12-\mathrm{h}$ light/dark cycle at $23 \pm 2{ }^{\circ} \mathrm{C}$ with a relative humidity of $65 \%$. Animals had free access to a standard pellet chow diet and tap water. The guidelines of the Committee for the Purpose of Control and Supervision of Experiments on Animals regarding the use and care of laboratory animals was followed for all of the experimental procedures and approval was obtained from the Institutional Animal Ethics Committee, Post Graduate Institute of Medical Education and Research (PGIMER), Chandigarh, India (IAEC no. 475 dated 30th January 2015).

\section{Drug preparation and administration}

PTZ was dissolved in $0.9 \%$ saline and injected intraperitoneally in a volume not exceeding $10 \mathrm{~mL} / \mathrm{kg}$ at a subthreshold dose of 35 $\mathrm{mg} / \mathrm{kg}$ on alternate days at 10:00 am. SV was also dissolved in 0.9\% saline and administered intraperitoneally at a dose of $200 \mathrm{mg} / \mathrm{kg} 30$ minutes prior $(9: 30 \mathrm{am})$ to the PTZ injection on alternate days. BBR was dissolved in $0.9 \%$ saline and administered orally at a dose of
$100 \mathrm{mg} / \mathrm{kg}$ daily using an oral gavage at 9:15 am and 45 minutes (9:15 am) prior to the PTZ injection on the day of PTZ administration. PTZ, SV, and BBR were administered for 10 weeks or until the animals became kindled. A single dose (100 mg/kg) of BBR was selected for the present mechanistic study based on previous studies. $^{13,14}$

\section{Chemical kindling procedure and behavioral response monitoring}

After PTZ injection, the rats were monitored for 1 hour for seizure scoring using the 1972 Racine scoring scale, ${ }^{15}$ as follows: stage 0 , no response; stage 1, facial and ear twitching; stage 2, myoclonic jerks without rearing; stage 3, myoclonic jerks with rearing; stage 4, turning over to a side position and clonic-tonic seizures; and stage 5, turning over to a back position and generalized tonic-clonic seizures. An animal was considered kindled if it was scored as stage 4 or higher in three consecutive trials. The effects of various treatments on sedation, locomotor activities, and any other abnormal behaviors were observed throughout the study period. No sedation, altered locomotor activities, or any abnormal behaviors were observed in any of the treatment groups.

\section{Study of the hippocampus and whole brain}

Animals were sacrificed by decapitation after an overdose of an anesthetic agent. The hippocampus was cautiously dissected out of the brain from the decapitated animals and subjected to histopathological scoring. The whole brain was used to study other parameters, which were assessed in triplicate and calculated per milligram of tissue protein.

\section{Histopathology of the hippocampus using hematoxylin and eosin staining}

After the hippocampus was dissected out, it was fixed with $10 \%$ formalin and subjected to hematoxylin and eosin staining. Degenerative changes in the neurons, such as cytoplasmic vacuolation, nuclear chromatin clumping, hyper eosinophilia, and condensed cytoplasm, and fragmentation of the cells were used to determine the relative percentage of neuronal damage by using the following semiquantitative histopathological scores: ${ }^{16}$

Normal or no injury $=0$

Rare neuronal injury ( $<5$ clusters $)=1$

Occasional neuronal injury (5-15 clusters) $=2$

Frequent neuronal injury ( $>15$ clusters $)=3$ 
Diffused neuronal injury $=4$

\section{Determination of lipid peroxidation through the estimation of MDA}

Tissue lipid peroxidation was evaluated by measuring TBA-reactive substances according to the method of Ohkawa et al. ${ }^{17}$ Tissue homogenate was prepared using the brain tissue and phosphate buffer (pH 7.2) at a ratio of $1 \mathrm{~g}$ of tissue to $9 \mathrm{~mL}$ of buffer. Sodium dodecyl sulphate, acetic acid solution, and a $0.8 \%$ aqueous solution of TBA was added to the supernatant of the homogenate. It was then heated at $95^{\circ} \mathrm{C}$ for 60 minutes. After cooling down to room temperature with tap water, butanol and pyridine at a ratio of 15:1 were added, and the mixture was shaken thoroughly. After centrifugation for 10 minutes at 4,000 rpm, the absorbance of the upper layer was determined at $530 \mathrm{~nm}$. The TBA-reactive substances used as MDA equivalents of the sample were estimated using an extinction coefficient of $1.56 \times 10^{5} \mathrm{~mol}^{-1} \mathrm{~cm}^{-1}$.

\section{SOD assay}

SOD was determined using the method of Kono. ${ }^{18}$ The aforementioned supernatant of the homogenate was incubated with nitroblue tetrazolium and hydroxylamine hydrochloride and monitored spectrophotometrically at $560 \mathrm{~nm}$. The percentage inhibition of the rate of nitroblue tetrazolium reduction to $50 \%$ of the maximum was then calculated as one unit of SOD activity.

\section{GPx assay}

GPx was determined using the method of Paglia and Valentine. ${ }^{19}$ The supernatant of the homogenate was incubated with GSH, hydrogen peroxide, and a reducible agent (dinitrobenzoic acid) and absorbance was determined at $340 \mathrm{~nm}$. The GPx activity was then measured indirectly as reduced nicotinamide adenine dinucleotide phosphate consumed per milligram of tissue protein.

\section{GSH assay}

The GSH level was estimated using the method of Sedlak and Lindsay. ${ }^{20}$ Dinitrobenzoic acid (a reducing substance) was added to the supernatant of the homogenate. The absorbance of the resulting product (nitromercaptobenzoic acid anion) was measured at 412 $\mathrm{nm}$, which indirectly determines the GSH level.

\section{DNA fragmentation study}

DNA was isolated using Trizol reagent and subjected to gel electrophoresis. The gel was then examined under ultraviolet light for any fragmentation of DNA in the sample.

\section{Gene expression study}

RNA was isolated using Trizol reagent and subjected to RT-PCR. The relative expression of the target genes (nrf2, bcl-2, bax, and caspase 3) was determined in each group using the RT-PCR comparative Ct method $(\Delta \Delta \mathrm{Ct})$ after normalization with $\beta$-actin as a reference

Table 1. Effects of various treatments on the seizure score and percentage of animals kindled in a model of pentylenetetrazole kindling in rats

\begin{tabular}{|c|c|c|c|c|}
\hline Time (weeks) & $\begin{array}{l}\text { Saline control } \\
\text { group }\end{array}$ & $\begin{array}{l}\text { Pentylenetetrazole control group } \\
\text { seizure score (percentage of } \\
\text { animals kindled) }\end{array}$ & $\begin{array}{c}\text { Sodium valproate }+ \\
\text { pentylenetetrazole group seizure } \\
\text { score (percentage of animals } \\
\text { kindled) }\end{array}$ & $\begin{array}{c}\text { Berberine }+ \text { pentylenetetrazole group } \\
\text { seizure score (percentage of animals } \\
\text { kindled) }\end{array}$ \\
\hline 1 & $0 \pm 0(0)$ & $2.63 \pm 0.70(25)$ & $1.73 \pm 0.52^{*}(0)$ & $2.00 \pm 0.00(0)$ \\
\hline 2 & $0 \pm 0(0)$ & $3.30 \pm 1.06(37.5)$ & $2.10 \pm 0.15^{*}(0)$ & $2.31 \pm 0.50(0)$ \\
\hline 3 & $0 \pm 0(0)$ & $3.73 \pm 1.06(37.5)$ & $2.23 \pm 0.31 *(0)$ & $2.45 \pm 0.73 *(12.5)$ \\
\hline 4 & $0 \pm 0(0)$ & $3.93 \pm 0.79$ (37.5) & $2.21 \pm 0.40 *(0)$ & $2.76 \pm 0.60 *(25)$ \\
\hline 5 & $0 \pm 0(0)$ & $4.10 \pm 0.58$ (37.5) & $2.31 \pm 0.39{ }^{* *^{\dagger}}(0)$ & $3.01 \pm 0.39 *(25)$ \\
\hline 6 & $0 \pm 0(0)$ & $3.98 \pm 0.80(37.5)$ & $2.16 \pm 0.40^{* *^{\dagger}}(0)^{* *^{\dagger}}$ & $3.03 \pm 0.35^{*}(37.5)^{\star}$ \\
\hline 7 & $0 \pm 0(0)$ & $4.00 \pm 0.77(50)$ & $2.35 \pm 0.37 *(0)^{* \prime \dagger}$ & $3.08 \pm 0.31 *(37.5)^{*}$ \\
\hline 8 & $0 \pm 0(0)$ & $4.18 \pm 0.47(62.5)$ & $2.15 \pm 0.16^{*^{\dagger \dagger}}(0)^{*^{\dagger \dagger}}$ & $3.28 \pm 0.39 *(37.5)^{*}$ \\
\hline 9 & $0 \pm 0(0)$ & $4.18 \pm 0.47(75)$ & $2.25 \pm 0.12^{*^{\dagger \dagger}}(0)^{* *^{\dagger}}$ & $3.38 \pm 0.39 *(37.5)^{\star}$ \\
\hline 10 & $0 \pm 0(0)$ & $4.18 \pm 0.47(75)$ & $2.25 \pm 0.12{ }^{*^{\prime \dagger}}(0)^{*^{* \dagger}}$ & $3.38 \pm 0.27^{\star}(37.5)^{\star}$ \\
\hline
\end{tabular}

Values are presented as mean \pm standard deviation (\%) or the mean (\%) $(n=6$ in the saline control group, $n=8$ in the pentylenetetrazole, sodium valproate, and berberine groups). One-way analysis of variance followed by Bonferroni post hoc analysis was applied to assess seizure scores. The chi square test was applied to the percentage of animals kindled.

${ }^{*} p<0.05$ compared to the pentylenetetrazole control group.

${ }^{\dagger} p<0.05$ compared to the berberine group. 
gene. The relative gene expression or fold change with respect to the PTZ control group was obtained using the formula $2^{-\Delta \Delta C t}$, and the PCR amplification efficiency of the target genes and the reference gene was assumed to be 2 (i.e., doubling of the amplicon each cycle). If the fold change was $\geq 1$, expression had increased, and if the value was $<1$, the gene expression had decreased with respect to the PTZ control group.

\section{Statistical analysis}

All data were expressed as the mean \pm standard deviation and statistical analysis was performed using the Statistical Package for the Social Sciences version 22.0 (International Business Machine Corp., Armonk, NY, USA). A one-way analysis of variance followed by a Bonferroni post hoc analysis was performed for quantitative parameters such as scoring of seizure, histopathology, antioxidant parameters (SOD, GSH, GPx, and MDA), and relative gene expression (nrf2, bcl-2, bax, and caspase 3). The chi square test was performed for the total percentage of animals kindled during the 10 weeks of PTZ treatment (35 mg/kg, i.p.).

A
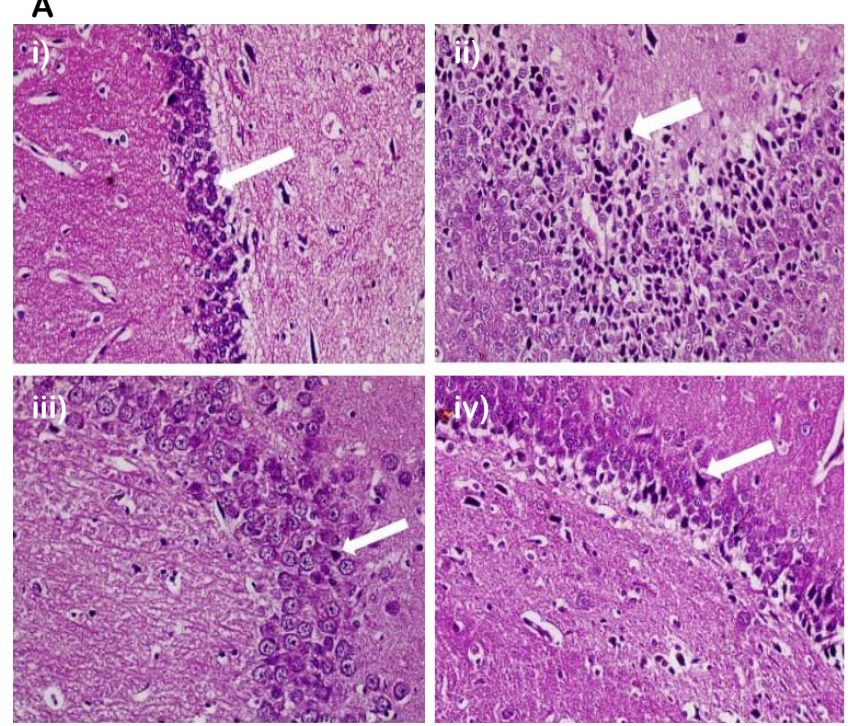

\section{Results}

\section{Seizure score and number of animals kindled in the model of PTZ kindling in rats}

The mean seizure score and animals kindled in all groups each week is shown in Table 1. PTZ (35 mg/kg, i.p.) administration showed a significant increase in the seizure score from $2.63 \pm 0.70(p<0.05)$ in the first week to $4.18 \pm 0.47(p<0.05)$ in the PTZ control group at the end of the 10-week study period compared to the SV+ PTZ and BBR + PTZ groups (Table 1). Furthermore, the number of kindled rats in the PTZ control group significantly increased in a time-dependent manner from $2 / 8(25 \%)$ in the first week to $6 / 8(75 \%, p<0.05)$ in the 10th week in comparison to the SV + PTZ $(0 \%, 0 / 8)$ and BBR + PTZ (37.5\%, 3/8) groups (Table 1).

\section{Effects of various treatments on degenerative changes and histopathological score of the hippocampus in the model of PTZ kindling in rats}

The saline solution did not affect neuron morphology in the saline control group; the neurons exhibited normal morphology with intact shapes, vesicular nuclei, and conspicuous and amphiphilic cytoplasm (Fig. 1).

\section{B}

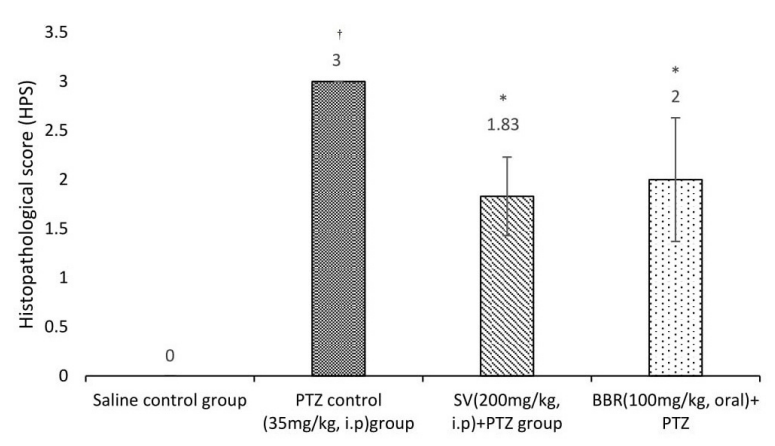

Figure 1. (A) Rat hippocampus microphotographs ( $\times 40)$ showing neuronal morphology in the different experimental groups. i) Saline control group (arrow), showing normal neuronal cells; ii) PTZ (35 mg/kg, i.p.) control group (arrow), showing diffuse neuronal injury of the cells; iii) SV + PTZ group (arrow), showing near-normal neuronal morphology; and iv) BBR + PTZ group (arrow), showing less damage than the PTZ group, indicating considerable protection. The arrow indicates neuronal damage. (B) Effect of various treatments on the histopathological scoring of the hippocampus in the model of PTZ kindling in rats. Data are expressed as the mean and bars indicate standard deviation ( $n=6$ in the saline control group, $n=8$ in the PTZ, SV, and BBR groups). One-way analysis of variance followed by Bonferroni post hoc analysis. PTZ, pentylenetetrazole; SV, sodium valproate; BBR, berberine. ${ }^{*} p<0.05$ compared to the PTZ control group. ${ }^{\dagger} p<0.05$ compared to the saline control group. 
Conversely, the PTZ control group showed frequent neuronal clusters and diffuse neuronal injury with a histopathological score (HPS) of $3.00 \pm 0.00$. The neurons in the SV+ PTZ group exhibited near-normal histology with an HPS of $1.83 \pm 0.40$ and the BBR + PTZ group showed few neuronal clusters with a significantly lower overall HPS of $2.0 \pm 0.63$ (Fig. 1) compared to the PTZ control group.

\section{Effect of various treatments on oxidative stress parameters in the whole brain in the model of PTZ kindling in rats}

\section{MDA levels}

In the PTZ control group, lipid peroxidation significantly increased according to estimations based on the rise in MDA levels. The brain MDA level was $602.41 \pm 229.80 \mathrm{nmol} / \mathrm{mg}$ of protein in the PTZ control group, which was significantly higher than that in the saline control group (215.31 $\pm 60.12 \mathrm{nmol} / \mathrm{mg}$ of protein, $p=0.003)$. In the SV + PTZ and BBR + PTZ groups, the brain MDA levels were 378.09 \pm 173.40 and $414.22 \pm 146.53 \mathrm{nmol} / \mathrm{mg}$ of protein, respectively, Fig. 2A) were lower than in the PTZ control group.

\section{GSH levels}

In the PTZ control group, the brain GSH level $(0.95 \pm 6.06 \mu \mathrm{m} / \mathrm{mg}$ of protein) was significantly lower than in the saline control group ( $2.64 \pm 0.44 \mu \mathrm{m} / \mathrm{mg}$ of protein, $p<0.0001$, Fig. 2B). The GSH levels in the SV + PTZ and BBR + PTZ groups ( $5.20 \pm 0.73$ and $6.29 \pm 1.65$ $\mu \mathrm{m} / \mathrm{mg}$ of protein, respectively) were significantly higher than in the PTZ control group $(p<0.0001)$.

\section{SOD levels}

The brain SOD level of rats in the PTZ control group was $10.18 \pm$ $6.73 \mathrm{IU} / \mathrm{mg}$ protein and that in the saline control group was $9.62 \pm$ $6.06 \mathrm{IU} / \mathrm{mg}$ of protein. However, the SOD level of the PTZ control group was significantly lower than that in the SV + PTZ (32.29 \pm $5.16 \mathrm{IU} / \mathrm{mg}$ of protein, $p=0.026)$ and BBR + PTZ $(43.72 \pm 21.42$ $\mathrm{IU} / \mathrm{mg}$ of protein, $p=0.001$ ) groups (Fig. 2C).

\section{GPx levels}

The brain GPx level in the PTZ control group was $0.01 \pm 0.00$ $\mathrm{mmol} / \mathrm{mg}$ of protein and that in the saline control group was $0.2 \pm$ $0.00 \mathrm{mmol} / \mathrm{mg}$ of protein. However, the GPx level in the PTZ control
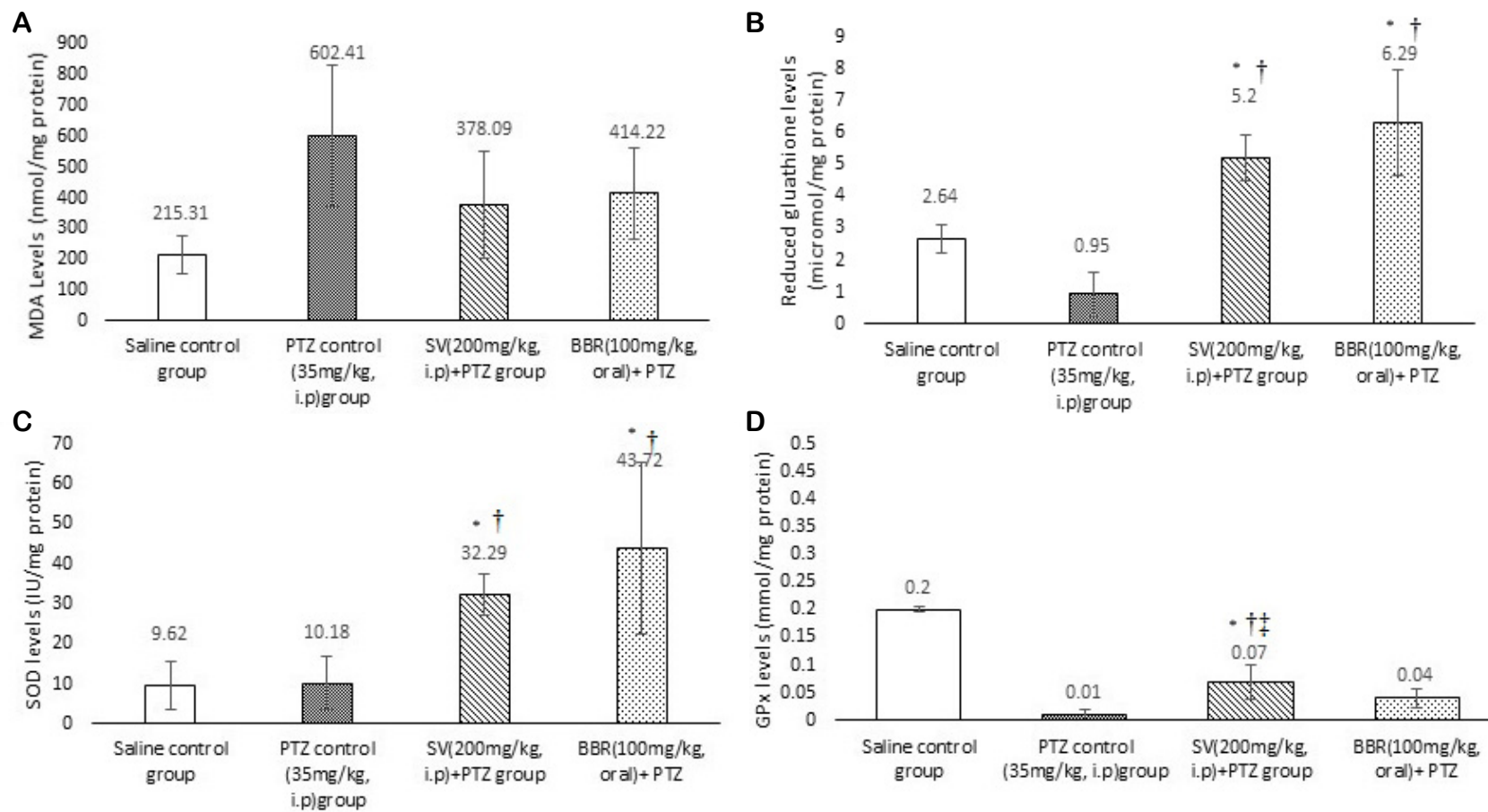

Figure 2. Effects of various treatments on the brain (A) MDA, (B) reduced glutathione, (C) SOD, and (D) Gpx levels in the model of PTZ kindling in rats. Data are expressed as the mean and bars indicate standard deviation ( $n=6$ in the saline control group, $n=8$ in the PTZ, SV, and BBR groups). One-way analysis of variance followed by Bonferroni post hoc analysis. MDA, malondialdehyde; PTZ, pentylenetetrazole; SV, sodium valproate; BBR, berberine; SOD, superoxide dismutase; GPx, glutathione peroxidase. ${ }^{\star} p<0.05$ compared to the saline control group. ${ }^{\dagger} p<0.05$ compared to the PTZ control group. ${ }^{\ddagger} p<$ 0.05 compared to the BBR group. 
group was significantly lower than that in the SV $+\mathrm{PTZ}(0.07 \pm 0.03$ $\mathrm{mmol} / \mathrm{mg}$ of protein, $p=0.0001)$ and BBR $+\mathrm{PTZ}(0.04 \pm 0.01$ $\mathrm{mmol} / \mathrm{mg}$ of protein, $p=0.049$ ) groups (Fig. 2D).

\section{Effects of various treatments on DNA fragmentation in brain tissue in the model of PTZ kindling in rats}

In the PTZ control group, the DNA fragmentation study showed highly prominent smearing in the genomic DNA. Conversely, no pattern was observed in the genomic DNA in the SV + PTZ (200 mg/kg), saline control, and BBR + PTZ (100 mg/kg) groups (Fig. 3).

\section{Effects of various treatments on the relative gene expression levels in rat brains}

In the saline control group, the relative expression of the anti-apoptotic bcl-2 gene (2.3-fold change) was greater than that of the PTZ control group, whereas that of the antioxidant gene nrf2 (0.3-fold change) and the pro-apoptotic genes bax (0.5-fold change) and caspase 3 ( 0.3 fold change) was lower than that of the PTZ control group. In the SV + PTZ group, expressions of all of the genes were greater than those in the PTZ control group. In the BBR + PTZ group, the relative expression of the bcl-2 (2.8-fold change) and bax genes (16.7-fold change) was greater than in the PTZ control group, whereas that of the nrf2 (0.8-fold change) and caspase 3 genes (0.5-fold change) was lower than in the PTZ control group (Fig. 4).

\section{$\begin{array}{lllllllllllll}\text { DL } & 1 & 2 & 3 & 4 & 5 & 6 & 7 & 8 & 9 & 10 & 11 & 12\end{array}$}

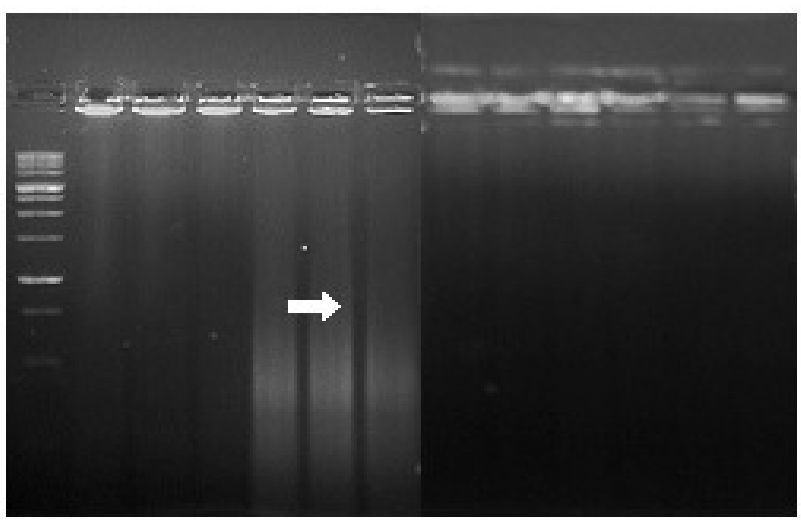

Figure 3. Effects of various treatments on DNA fragmentation in the brain tissue in the model of PTZ kindling in rats. Arrow showing the smearing. Lanes 1-3: saline control group; lanes 4-6: PTZ control group (35 mg/kg, i.p.); lanes 7-9: sodium valproate + PTZ group; lanes 10-12: berberine + PTZ group. DL, DNA ladder; PTZ, pentylenetetrazole.

\section{Discussion}

In previous studies of acute models of epilepsy, BBR reduced the number of animals developing status epilepticus and spontaneous seizures. ${ }^{13,14}$ In a study by Mojarad and Roghani, ${ }^{14}$ BBR demonstrated $90 \%$ protection against developing status epilepticus and $80 \%$ protection against developing spontaneous seizures in a kainate model of status epilepticus. In PTZ control group, the mean seizure score increased between the start of PTZ administration and the 10th week. But in the SV + PTZ and BBR + PTZ groups, there were no such increase in the seizure score between the start of PTZ administration and the 10th week. Furthermore, $75 \%$ of the animals in the PTZ control group developed kindling after 10 weeks, whereas the animals in the SV + PTZ group were not kindled during the 10 -week study period. This supports previous studies and protocols in which the maximum number of animals was kindled in PTZ control groups. ${ }^{21}$ In the BBR + PTZ group, 37.5\% of the animals developed kindling at the end of 10 weeks, which was significantly lower than in the PTZ control group. The present study showed that BBR may have antiepileptic action by revealing a 50\% reduction in the number of animals kindled in comparison to the PTZ control group, although

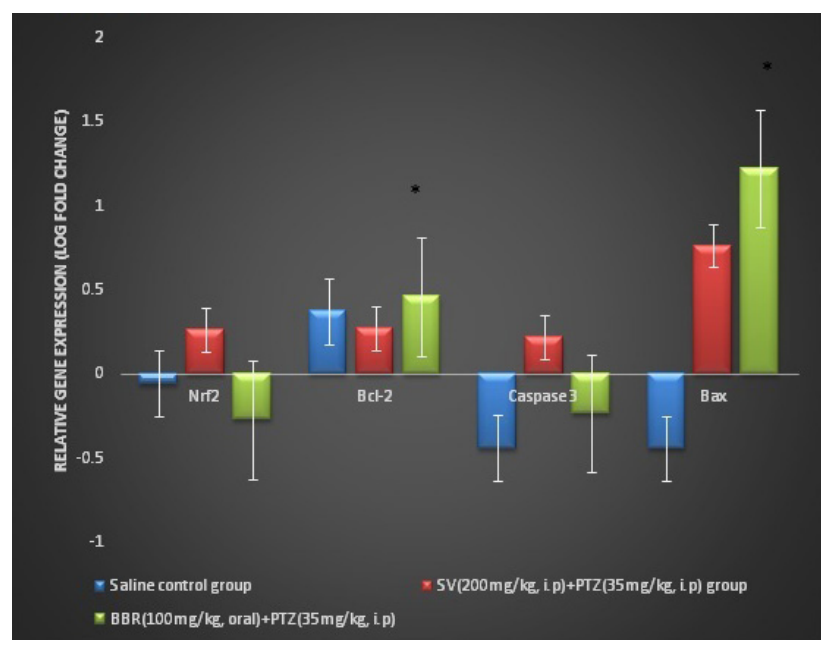

Figure 4. Effects of various treatments on the relative gene expression in the brain in the model of PTZ kindling in rats. Log fold change $(<0$ indicates lower expression, $>0$ indicates greater expression) in the expression of the target genes (nrf2, bcl-2, bax, and caspase 3) in the saline control, SV, and BBR groups compared to the PTZ control group after normalization with a reference gene ( $\beta$-actin). One-way analysis of variance followed by Bonferroni post hoc analysis ( $n=6$ in the saline control group, $n=8$ in the PTZ, SV, and BBR groups. SV, sodium valproate; PTZ, pentylenetetrazole; $\mathrm{BBR}$, berberine. ${ }^{*} p<0.05$ compared to the saline control group. Bars indicate standard deviation. 
the action was less effective than SV, which showed 100\% protection against the development of kindling in rats.

The histopathological scores in this study indicated the estimated damage to localized regions of the brain, mainly the hippocampal region, and do not represent neuronal damage to the whole brain. The PTZ kindled rats showed diffuse neuronal injury, indicating considerable neuronal damage caused by repeated seizures. The SV + PTZ and BBR + PTZ groups had less neuronal damage than the PTZ control group, with some neurons in the CA1 and CA3 regions demonstrating neuroprotective properties.

Similar to previous studies, in the present study, PTZ induced oxidative stress and the brain MDA level in the PTZ control group was significantly elevated compared to that in the saline control group. Both SV and BBR reduced the increase in brain MDA levels. 15,17 Mojarad and Roghani ${ }^{14}$ and Gao et al. ${ }^{22}$ demonstrated that BBR significantly ameliorated lipid peroxidation compared to non-treated epileptic animals. The SOD level was significantly lower in the PTZ control group than in the saline control, SV + PTZ, and BBR + PTZ groups. This contradicted the result of a previous study in which BBR exerted no effects on SOD levels in a pilocarpine-induced epilepsy model in rats. ${ }^{22}$ In addition, the PTZ control group had a lower level of GSH than that reported in previous studies, indicating increased production of free radicals and that the GSH level was depleted during the process of defending against oxidative stress. ${ }^{23} \mathrm{SV}$ and BBR reversed this decrease in glutathione levels in the PTZ kindled animals, suggesting their free radical scavenging potential. BBR showed similar results in a previous study in which kainate reduced glutathione levels and BBR reversed this effect. ${ }^{23}$ The SV + PTZ and BBR + PTZ groups had lower GPx enzyme levels, indicating that both SV and BBR increase the expression of this enzyme, thereby increasing the level of GSH.

In the DNA fragmentation study, the PTZ control group showed a highly prominent smearing pattern in the genomic DNA, indicating the degradation of genomic DNA caused by the chronic seizures induced by PTZ. However, the saline control, SV + PTZ, and BBR + PTZ groups did not show any smearing of genomic DNA, indicating that treatment with SV and BBR reduced the occurrence of seizures, which in turn reduced apoptosis and DNA fragmentation of neuronal cells.

Preclinical evidence has shown that transient as well as repeated seizures can cause neuronal cell death and oxidative stress, including changes at the molecular level within the hippocampus. ${ }^{24,25}$ The neuronal cell death may be due to the activation of pro-apoptotic pro- teins such as caspases and bax, bim, and bid. ${ }^{24}$ The oxidative stress may be associated with antioxidant nrf2 protein activation leading to the generation of antioxidant defense enzymes. ${ }^{7}$ In the present study, $\beta$-actin (a housekeeping gene) was expressed in the brains of rats in all treatment groups. In the saline control group, the expression of the pro-apoptotic proteins bax and caspase 3 and the antioxidant protein nif2 was lower, whereas that of the anti-apoptotic protein bcl-2 was higher, indicating no molecular changes in the non-diseased rats. The relative expression of the $\mathrm{nrf2}$, bcl-2, bax, and caspase 3 genes in the rat brains was greater in the SV group than in the PTZ control group. In the BBR + PTZ group, the relative expression of the pro-apoptotic gene bax was higher than that of the saline control and SV + PTZ groups. However, the expression of the protective bcl-2 gene was higher and that of the apoptotic caspase 3 gene was lower in the BBR + PTZ group, and the latter may explain the lack of DNA fragmentation. Furthermore, the expression of the nrf2 gene was lower, which may explain the few neuronal clusters seen in the histopathological changes in the hippocampus caused by oxidative stress. This may have been due to the administration of BBR prior to the PTZ injection reducing oxidative stress. However, this result contradicts previous studies that showed that BBR activates the nrf2 gene, which might be responsible for its neuroprotective and antiepileptogenic effects in various neurodegenerative animal models. ${ }^{10,13}$ This may be due to the dose of $B B R(100 \mathrm{mg} / \mathrm{kg}$ ) being insufficient to activate the nrf2 pathway in the present study.

The results indicated that the neuroprotective mechanism of BBR could be due to its effects on apoptotic regulatory pathways through the activation of the anti-apoptotic protein bcl-2 and the prevention of cell death and oxidative stress. Daily administration of BBR reduced seizure severity and the number of animals kindled at the end of drug administration. Thus, this study provides a basis for further investigation into the possible mechanisms of BBR in the prevention of epileptogenesis.

\section{Acknowledgements}

The authors gratefully acknowledge the technical assistance provided by senior technician Mr. P.J. Thomas and colleague Mrs. Neha Singh for helping in performing the genetic study. The study was funded by intramural funding.

\section{Conflicts of Interest}

The authors declare that they have no conflicts of interest. 


\section{References}

1. World Health Organization (WHO). Epilepsy, 2010 [Internet]. Geneva: WHO, [cited 2016 Dec 10]. Available at : http://uww.who.int/mediacentre/factsheets/fs999/en/index.html.

2. Marieb EN, Wilhelm PB, Mallatt JB. Human anatomy and physiology. In: Marieb EN, Hoehn K, eds. Neuronal networks in human epilepsy. 6th ed. San Francisco: Pearson Education Inc and Dorling Kindersley Publishing Inc, 2006;430-488.

3. Lowenstein DH, et al. Harrison's Principles of Internal Medicine. In: Longo DL, Fauci AS, Kasper DL, Hauser SL, Jameson JL, Joseph L, eds. Diseases of the central nervous system. 18th ed. New York: McGraw-Hill, 2008;2498-2512.

4. Lugrin J, Rosenblatt-Velin N, Parapanov R, Liaudet L. The role of oxidative stress during inflammatory processes. Biol Chem 2014;395:203-230.

5. Pitkänen $A$, Lukasiuk K. Mechanisms of epileptogenesis and potential treatment targets. Lancet Neurol 2011;10:173-186.

6. Vezzani A, Friedman A, Dingledine RJ. The role of inflammation in epileptogenesis. Neuropharmacology 2013;69:16-24.

7. Wang $W, W u Y$, Zhang $G$, et al. Activation of Nrf2-ARE signal pathway protects the brain from damage induced by epileptic seizure. Brain Res 2014; 1544:54-61.

8. Mathern GW, Babb TL, Armstrong DL. Hippocampal Sclerosis. In: Michelle Bureau, Pierre Genton, Charlotte Dravet, Antonio V. Delgado-Escueta, Carlo Alberto Tassinari, Pierre Thomas \& Peter Wolf, eds. Epilepsy: a comprehensive textbook. 5th ed. Paris : John Libbey Eurotext, 1997;133-155.

9. Graham SH, Chen J, Stetler RA, Zhu RL, Jin KL, Simon RP. Expression of the proto-oncogene bcl-2 is increased in the rat brain following kainate-induced seizures. Restor Neurol Neurosci 1996;9:243-250.

10. Birdsall TC. Berberine: therapeutic potential of an alkaloid found in several medicinal plants. Altern Med Rev 1997;2:94-103.

11. Hsu YY, Chen CS, Wu SN, Jong YJ, Lo YC. Berberine activates Nrf2 nudear translocation and protects against oxidative damage via a phosphatidylinositol 3-kinase/Akt-dependent mechanism in NSC34 motor neuron-like cells. Eur J Pharm Sci 2012;46:415-425.

12. Kwak MK, Itoh K, Yamamoto M, Kensler TW. Enhanced expression of the transcription factor Nrf2 by cancer chemopreventive agents: role of antioxidant response element-like sequences in the nif2 promoter. Mol
Cell Biol 2002:22:2883-2892.

13. Bhutada P, Mundhada Y, Bansod K, Dixit P, Umathe S, Mundhada D. Anticonvulsant activity of berberine, an isoquinoline alkaloid in mice. Epilepsy Behav 2010;18:207-210.

14. Mojarad TB, Roghani M. The anticonvulsant and antioxidant effects of berberine in kainate-induced temporal lobe epilepsy in rats. Basic Clin Neurosci 2014;5:124-130.

15. Racine RJ. Modification of seizure activity by electrical stimulation. II. Motor seizure. Electroencephalogr Clin Neurophysio/ 1972;32:281-294.

16. Myung $R$, Petko $M$, Judkins $A R$, et al. Regional low-flow perfusion improves neurologic outcome compared with deep hypothermic circulatory arrest in neonatal piglets. J Thorac Cardiovasc Surg 2004;127:1051-1056; discussion 1056-1057.

17. Ohkawa $H$, Ohishi N, Yagi K. Assay for lipid peroxides in animal tissues by thiobarbituric acid reaction. Anal Biochem 1979;95:351-358.

18. Kono Y. Generation of superoxide radical during autoxidation of hydroxylamine and an assay for superoxide dismutase. Arch Biochem Biophys 1978;186:189-195.

19. Paglia DE, Valentine WN. Studies on the quantitative and qualitative characterization of erythrocyte glutathione peroxidase. J Lab Clin Med 1967;70:158-169.

20. Sedlak J, Lindsay RH. Estimation of total, protein-bound, and nonprotein sulfhydryl groups in tissue with Ellman's reagent. Anal Biochem 1968;25: 192-205.

21. Gupta YK, Veerendra Kumar MH, Srivastava AK. Effect of centella asiatica on pentylenetetrazole-induced kindling, cognition and oxidative stress in rats. Pharmacol Biochem Behav 2003;74:579-585.

22. Gao B, Doan A, Hybertson BM. The clinical potential of influencing Nrf2 signaling in degenerative and immunological disorders. Clin Pharmacol 2014;6:19-34.

23. Schulz JB, Lindenau J, Seyfried J, Dichgans J. Glutathione, oxidative stress and neurodegeneration. Eur J Biochem 2000;267:4904-4911.

24. Henshall DC, Clark RS, Adelson PD, Chen M, Watkins SC, Simon RP. Alterations in bcl-2 and caspase gene family protein expression in human temporal lobe epilepsy. Neurology 2000;55:250-257.

25. Cheng Y, Sun AY. Oxidative mechanisms involved in kainate-induced cytotoxicity in cortical neurons. Neurochem Res 1994;19:1557-1564. 